\title{
Article \\ Forest Bio-Hubs to Enhance Forest Health While Supporting the Emerging Bioeconomy-A Comparison between Three U.S. Regions
}

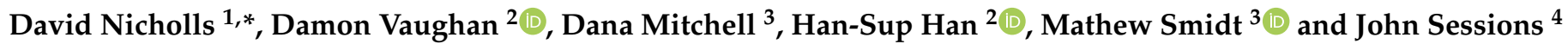 \\ 1 Pacific Northwest Research Station, USDA Forest Service, Juneau, AK 99801, USA \\ 2 Ecological Restoration Institute, Northern Arizona University, Flagstaff, AZ 86011, USA; \\ Damon.Vaughan@nau.edu (D.V.); Han-Sup.han@nau.edu (H.-S.H.) \\ 3 Southern Research Station, USDA Forest Service, Auburn, AL 36849, USA; Dana.Mitchell@usda.gov (D.M.); \\ Mathew.Smidt@usda.gov (M.S.) \\ 4 Forest Engineering, Resources \& Management, College of Forestry, Oregon State University, \\ Corvallis, OR 97331, USA; John.Sessions@oregonstate.edu \\ * Correspondence: David.1.Nicholls@usda.gov
}

check for updates

Citation: Nicholls, D.; Vaughan, D.; Mitchell, D.; Han, H.-S.; Smidt, M.; Sessions, J. Forest Bio-Hubs to Enhance Forest Health While Supporting the Emerging Bioeconomy-A Comparison between Three U.S. Regions. Energies 2022, 15, 931. https://doi.org/ 10.3390/en15030931

Academic Editor: Idiano D'Adamo

Received: 19 November 2021

Accepted: 12 January 2022

Published: 27 January 2022

Publisher's Note: MDPI stays neutral with regard to jurisdictional claims in published maps and institutional affiliations.

Copyright: (C) 2022 by the authors. Licensee MDPI, Basel, Switzerland. This article is an open access article distributed under the terms and conditions of the Creative Commons Attribution (CC BY) license (https:// creativecommons.org/licenses/by/ $4.0 /)$.

\begin{abstract}
The emerging bioeconomy requires new supply chain paradigms for biomass materials to reach processing centers. Forest bio-hubs can be thought of as networks of collection points to facilitate biomass supply chains that feed from forest to central processing facilities. The design and functionality of forest bio-hubs depends on the form (e.g., vertically and horizontally integrated), and the quality and volume of feedstocks. In this paper we conceptually develop the potential role of forest bio-hubs. We then compare current bio-hub development in three U.S. regions-the Pacific Northwest, the southwest region, and the southeastern U.S. We use a "SWOT" framework to compare strengths, weaknesses, opportunities, and threats for each region. We consider transportation distances, topography, proximity to markets, harvesting methods, and wood products development. Innovation and adaptability would play key roles in forest bio-hub development, especially with dynamic conditions related to markets, wildfire risks, biomass utilization policy, and community socioeconomic factors.
\end{abstract}

Keywords: forest depot; bio-hub; biomass supply chain; biorefinery; log sort yard; wood yard

\section{Introduction}

\subsection{Forest Bio-Hubs: Context and Definition}

There is a need to scale up the capacity of biorefineries producing liquid fuel from bio-based feedstock in order to meet targets set by the Renewable Fuels Standards [1] and other initiatives. At the same time, restoration of western U.S. forests is creating an abundance of woody material that has limited markets [2]. Forest bio-hubs, a potential solution to both of these problems, can be thought of as networks of collection points to facilitate biomass supply chains linking forests to a central processing facility. However, forest bio-hubs can be different in format, function and definitions, and this can vary by region, forest type, processing technologies, and scale of utilization. Forest bio-hubs have numerous advantages in supplying wood and biomass to manufacturing facilities compared to traditional biomass transportation chains and can result in more efficient and economical feedstock transportation. A key characteristic of forest bio-hubs is that they include some level of intermediate biomass processing, from minimal to more sophisticated. Examples include drying, chipping, grinding, torrefaction, pelletizing, biochar production, and pyrolysis oil. Forest bio-hubs can incorporate a variety of biomass feedstocks including forest residues, mill residues, agricultural residues, and municipal solid wastes. Effective forest bio-hubs can also enable a wide diversity of bio-products produced at a central biorefinery, and could play a key role in the future development of the bioeconomy. 
In this paper, we define a bio-hub as a collection that includes the following essential components: (1) a biorefinery that could produce a number of end products such as cellulosic ethanol, energy, or bio-chemicals; (2) any number of intermediate processing facilities often referred to as depots, supplying the centralized facility; (3) harvest sites; and (4) transportation connections between these elements. The term bio-hub refers to the entire supply chain, including transportation legs, intermediate processing facilities, and the central biorefinery. Bio-hub elements could be state- or privately-owned Figure 1 shows an example bio-hub configuration (Figure 1b) compared to a traditional supply chain (Figure 1a).
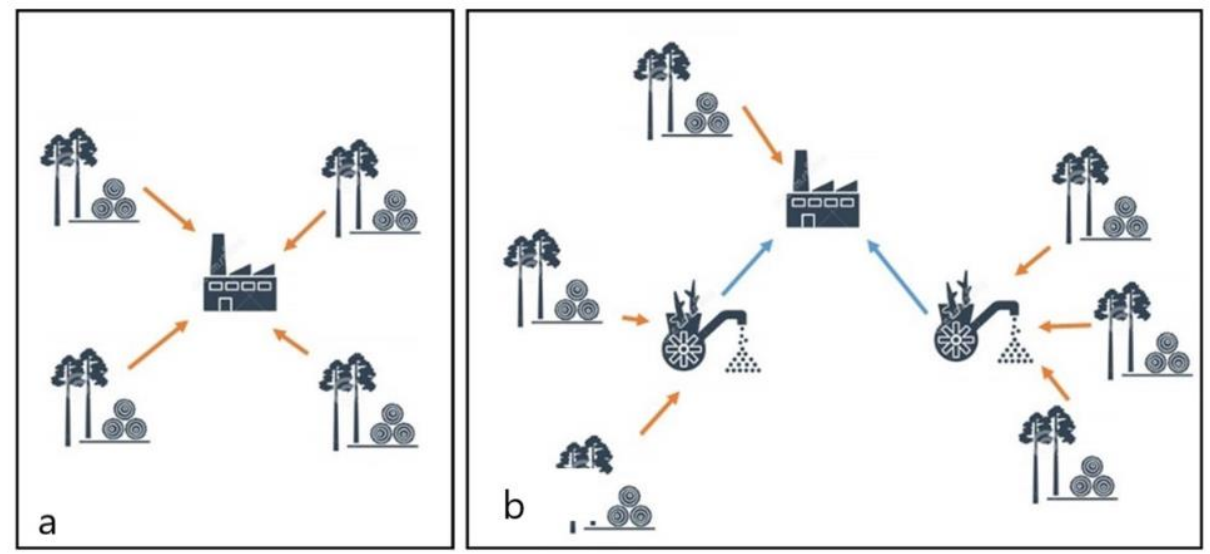

Figure 1. (a). traditional forest biomass supply chain, showing transportation from forest directly to central manufacturing facility; (b). bio-hub configuration, showing intermediate processing centers located between forest and central processing facility.

\subsection{Overview of Bio-Hub Research}

The concept of "advanced uniform feedstock design systems" [3], a pre-cursor to the bio-hub idea, refers to a distributed supply chain where strategically placed depots are used to pre-process biomass and provide a uniform feedstock to centralized biorefineries. These depots serve to improve the flowability, transportability (bulk density), and stability/storability (dry matter loss reduction) of the biomass [3]. Many techno-economic studies have compared this approach to "conventional systems", primarily with regard to agricultural residues [4,5] but occasionally focusing on forestry residues [6]. One of the major advantages of the advanced system is that it can de-risk the supply chain for the biorefinery and reduce the spatial variability of feedstock costs, often leading to lower interest rates for investments. The drawbacks of such a system are that it can add considerable processing and transportation costs for feedstock procurement.

Generally, as the procurement radius increases, or the capacity of the biorefinery increases, the advanced uniform system becomes competitive with conventional systems and eventually can lead to cost reductions [4]. This can be aided by multi-modal transportation, for example truck transport to the depot for pre-processing and blending, followed by rail transport to the central refinery [4]. To reduce capital investment costs, Martinkus et al. (2018) [7] explored repurposing existing sites rather than building greenfield facilities, and provided a decision support tool to help with siting these facilities (Figure 2). Muth et al. (2014) [6], regarding forestry residues in the southeastern US, concluded that the advanced feedstock system slightly raised the "minimum ethanol selling price" for a biorefinery as compared to the conventional system. The benefits provided were reduced moisture and ash in the system (improving storage and conversion processes), and a reduced supply chain risk for processing facilities. These examples serve to highlight the fact that in some cases distributed supply chains can lead to benefits, but in others their added complexity may not pay off. 


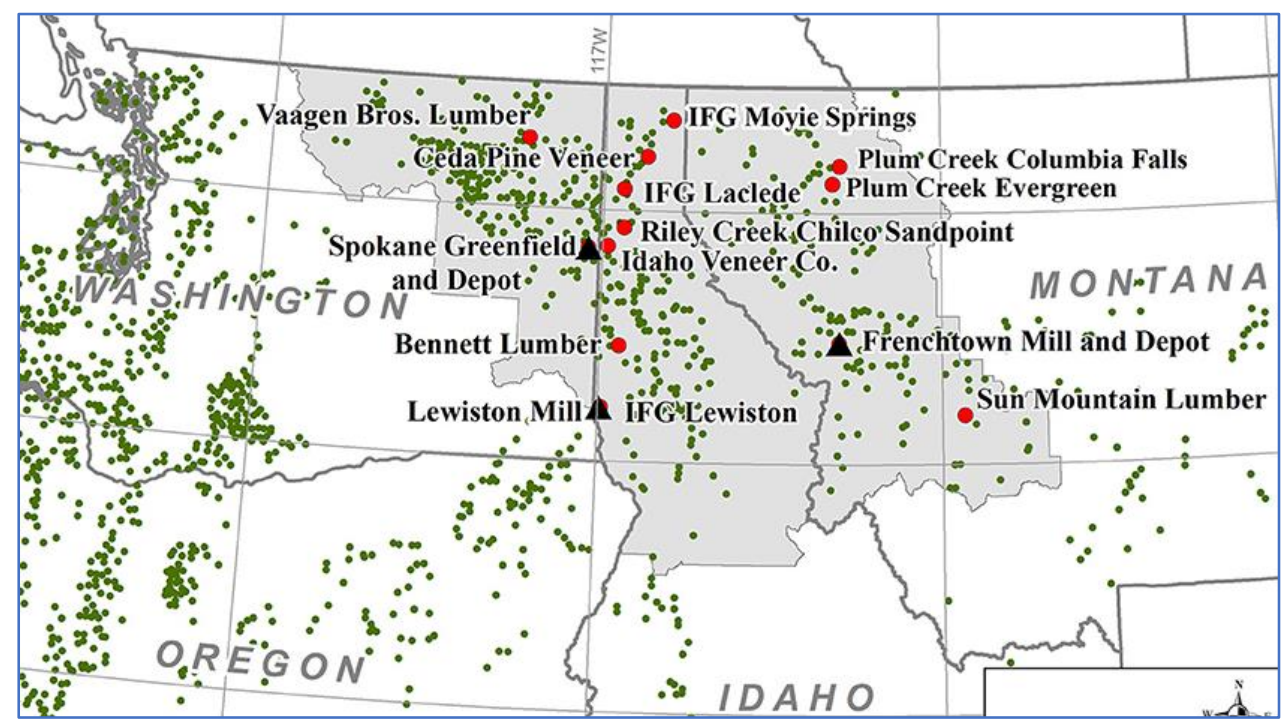

Figure 2. Proposed forest depot configuration in northern WA, ID and MT. Included are processing facilities (black triangles), forest depots (red circles), and biomass sources (green dots). Source: Martinkus et al., 2018.

Internationally, forest bio-hubs have gained increasing attention, including recent work by the International Energy Agency [8] to consider supply chain structures conducive for biorefineries. The IEA Bioenergy work plan identifies a need to explore "The role of preprocessing or pre-treatment of biomass at different points in the supply chain to increase the value and quality of biomass for given technologies" [8]. An essential element of a biohub is the scale and volume of biomass feedstocks processed. Large-scale biorefineries receiving feedstocks from multiple depots could produce a range of products including bioplastics, automotive fuels, aviation fuels, thermal and/or electrical energy. This research has been largely motivated by cellulosic ethanol production, focusing on agricultural residues [9]. Often bio-hub operations can be formulated as multi-commodity network. Others have considered the role of innovation in forestry operations using an SWOT analysis framework [10].

\subsection{Forest Bio-Hubs in U.S. Forests}

There are few working examples of forest bio-hubs in U.S. forests, but there are examples of some of the components (depots, biorefineries), and development of some fullscale forest bio-hubs may be on the horizon. In the southeastern U.S., wood pellet exports to Europe provide a large-scale example in which the depots are located in the U.S. and provide a uniform feedstock (i.e., pellets) to central processing facilities in Europe [11,12]. By allowing access to faraway markets, forest bio-hubs could provide clear benefits in areas that have under-developed markets for wood products. In the Southwest, this approach was tested at the pilot scale in 2019 , when researchers shipped approximately (1270 metric tons) of wood chips to South Korea for bioenergy markets [13]. In other cases, forest bio-hubs might not have clear advantages versus traditional biomass supply chains, especially when large biomass volumes are processed and handled multiple times under short transportation distances (versus transporting biomass directly to its end use location) [14].

The use of forest bio-hubs to manage forest residues could facilitate the Collaborative Forest Landscape Restoration Program (CFLRP) that the USDA Forest Service has underway in many western states (Figure 3). A goal of the CFLRP is to "encourage the collaborative, science-based ecosystem restoration of priority forest landscapes" [15], with a key feature being to utilize woody biomass from restoration treatments. Other objectives include promoting the ecological, economic, and social sustainability, while leveraging local resources to accomplish forest management goals [16]. Often, this involves local 
organizations such as non-profits and private entities to train workers who carry out forest restoration activities [17].

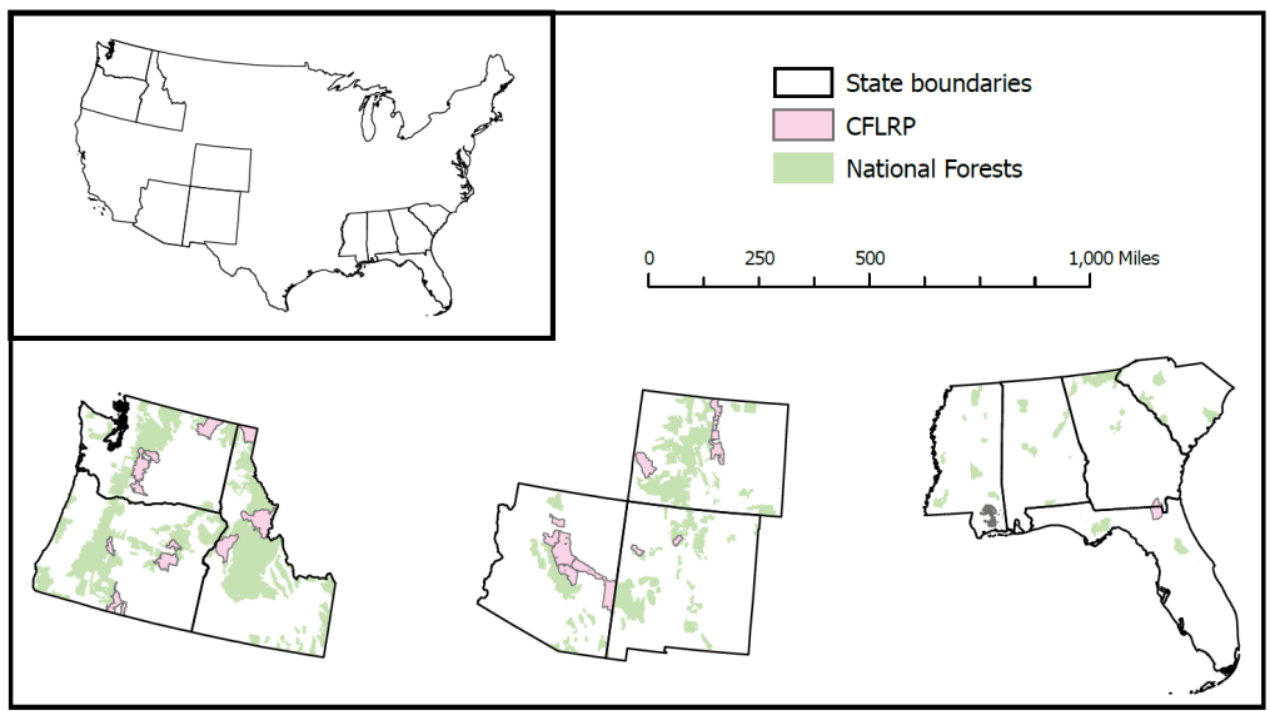

Figure 3. The three U.S. regions detailed in this paper: the Pacific Northwest (left), the southwest (center), and the southeast (right). National Forest land is shown in green shading and Collaborative Forest Restoration Projects are shown as pink polygons.

An overarching goal of biomass removals in many western forests is to reduce wildfire risks. Thus, biomass utilization within the framework of forest bio-hubs can provide an array of benefits for forest-dependent communities. Modern megafires are driven both by climate change and fuel buildup that has resulted from past land management practices. Proper forest management can not only address fuel buildup but also make forests more climate resilient. Local use of forest resources can result in greater employment while reducing fire risk at community-forest interfaces [18]. At the landscape level, mechanical removal of small-diameter trees in overstocked stands can also provide numerous forest health benefits [19]. Over the past several decades, many western wood products facilities have closed or now operate at reduced capacities. Given new paradigms for timber harvest and use, including increased utilization of small-diameter logs and forest residues, innovative approaches are needed for adding value to forest resources. Connecting various manufacturing facilities through forest bio-hubs requires new infrastructure, transportation systems, and workforce skills versus traditional models. Although forest bio-hubs have many potential advantages, their feasibility must be assessed on an individual basis to determine the specific benefits present and whether they can be economically justified versus conventional supply chain structures. Increasingly, bio-hub supply chains can lead to socially accepted practices regarding sustainability of forest resources and provision of ecosystem services such as enhancing water quality and reducing wildfire risk. This broad-based acceptance is expected to continue as new innovative bio-based products reach commercialization as part of the bioeconomy.

\subsection{Scope and Objectives}

This paper explored potential pathways for bio-hub development in the U.S. to facilitate the sustainable use of biomass. Bio-hub development in three U.S. regions was considered- the Pacific Northwest, the southwest, and the southeast. We felt it was important to include all 3 of these regions since they encompass some of the primary timber producing regions, while having distinctly different forest types, harvesting conditions, mill structures, and markets. We considered it outside the scope of this paper to conduct economic analyses of the feasibility of a bio-hub approach, due to the variability involved. For each region, we used a "SWOT" analysis format (strengths, weaknesses, opportunities, and 
threats). Here SWOT refers to strengths and weaknesses of forest bio-hubs in a given region, comparing traditional biomass supply chains to forest bio-hubs. We did not explicitly make interregional comparisons of strengths and weaknesses, although these points become apparent in the discussion. We considered only forest-derived woody biomass, including logging residue from traditional timber harvesting, thinnings, restoration treatments, and purpose grown energy woody crops [20] in addition to wood products manufacturing residues. Not included are municipal solid wastes or agricultural residues.

The two specific objectives of this research were:

1. To provide regional summaries of three U.S. regions regarding what bio-hub configurations are closest to being commercialized, and

2. To conduct a "SWOT" assessment of the three regions regarding forest bio-hub potential

\section{Summary of Forest Bio-Hub Potential in Three Regions}

\subsection{Pacific Northwest Region}

The Pacific Northwest region (PNW) can be characterized as having a thriving industry on private forestlands with established milling infrastructure, although domestic consumers for pulp chips have been declining for several years. Pulp chip markets do not exist in Northern California and pulp chips face long transport distances in many areas east of the Cascades. There is a need for forest restoration on public lands, particularly east of the Cascades. Biomass pre-processed at depots could facilitate transportation as well as provide product diversification. A large private and public land base, low electricity rates in much of the region, barge and rail access, and a developed forestry infrastructure are regional strengths.

A number of collection points exist in the Pacific Northwest between the forest and the processing facility which serve to add value to various forestry feedstocks. They are much simpler than the depots proposed by Lamers et al. (2015b) [5] and can include some level of in-woods or near-woods biomass processing (for example drying, chipping, grinding, log bucking). Successful examples, illustrated in Figure 4, include chip yards (e.g., Hermann Brothers Port Angeles), transfer yards, sort yards (e.g., Thompson Sort Yard), merchandizing yards, and centralized landings (e.g., Steve Morris, Arcata, CA) for in-woods grinding. To date, no biorefineries in the Pacific Northwest plan to use satellite depots to preprocess their feedstock in the format suggested by Lamers et al. (2015b) [5]. The Red Rock Biofuels plant scheduled to start up in Lakeview, Oregon will use forest biomass delivered directly by truck from the forest to the biorefinery. Delta Airlines, before COVID-19, was reportedly considering constructing a biorefinery in western Washington. It would use direct delivery of ground forest harvest residues from the forest to the biorefinery. Centralized landings for accumulating and densification of biomass may be part of the supply chain.

Although several recent studies in the Pacific Northwest have shown forest bio-hubs could be economically viable, particularly at longer transport distances, the two most likely biorefineries to be constructed in the short term will likely not use forest bio-hubs due to relatively short transport distances from forest to facility. Simpler aggregation and conversion facilities such as chip yards, sort yards, and centralized landings would continue where economically viable. A demand for biofuels that exceeds the biomass supply potential of westside industrial forest lands coupled with a dependable supply of biomass from public dry forest restoration programs could bring the forest biomass bio-hub concept to fruition. 

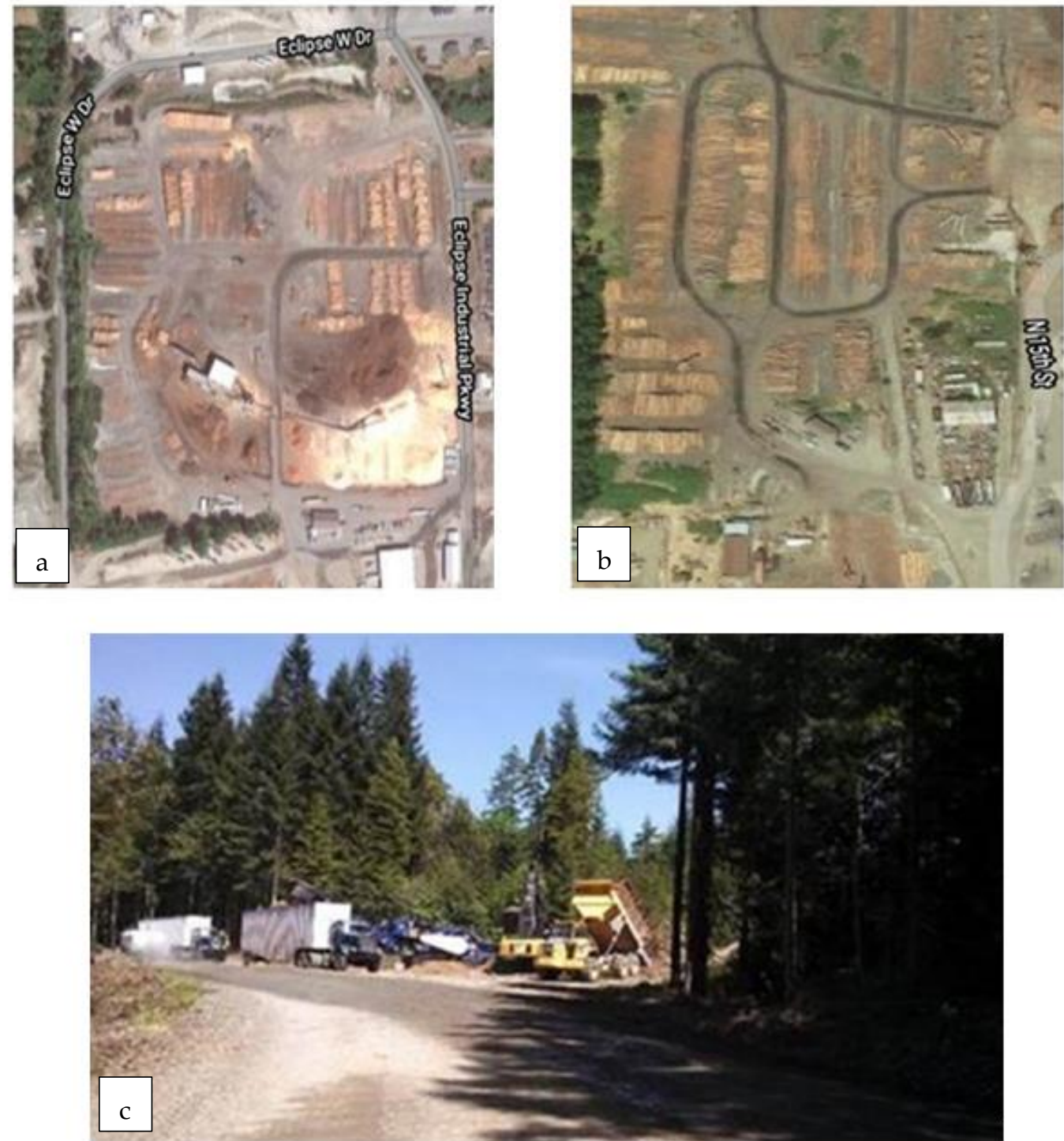

Figure 4. (a). (upper left) Hermann Brothers chip yard, Port Angeles, WA. (b). (upper right) Thompson Merchandizing Yard. (c). (bottom center) Centralized landing showing delivery of forest harvest residues by off-highway dump truck, grinding, and transport by all-wheel drive truck to paved road staging area for transport by on-highway truck to power plant. (Steve Morris contractor, Arcata, CA, USA).

\subsection{Southwest Region}

The Southwestern U.S. has high levels of public ownership of forestlands (68 percent in Colorado, 57 percent in New Mexico, and 61 percent in Arizona), and today's forest management activities on these public forestlands often focus on improving forest health and reducing wildland fire hazard. For example, several Collaborative Forest Landscape Restoration Projects (CFLRPs), which are large projects that can have contracts of up to 20 years with possibility for renewal, are underway throughout the region. Smalldiameter trees and biomass resulting from forest restoration thinning treatment activities are not fully utilized and are often wasted (e.g., burned or decayed) on site due to low value and lack of market for those materials. Poor utilization of small-diameter trees and biomass, referred to as the "biomass bottleneck", has been a key barrier to successful implementation of forest restoration activities on public forestlands. Active management of private forestlands in this region augments timber resources available for manufacturing wood-based products. Existing markets for woody materials include pallets, house logs, 
hog fuel, pellets, lumber, and firewood. Firewood is currently a particularly large sector due to the prevalence of small-diameter and low-quality timber, high product demand, and low capital investment requirements.

Public and community support has been identified as essential to successfully implement fuel reduction programs [21]. For example, voters in Flagstaff, Arizona voted in 2012 to approve a ten-million-dollar bond for forest restoration on city land and neighboring national forest land [22]. Much of this community support has arisen since stakeholders realize the full cost of wildfires, including post-fire flooding, is vastly greater than the cost of preventative forest restoration [23]. Nicholls (2014) [24] further emphasized the need for coordinated wood and biomass utilization efforts to increase as broad-scale restoration treatments across Arizona's national forests remove large amounts of wood fiber. However, the skilled timber harvesting and transportation workforce is currently limiting in this region, especially if large-scale forest restoration projects ramp up in coming years [25].

The Southwest may most effectively contribute to U.S. bio-hub development by providing a source of raw and pre-processed wood for existing markets elsewhere. Due to a lack of existing markets for wood and the instability of the supply from public forestland, development of a central biorefinery would be an unlikely endeavor in the Southwest. However, pre-processing depots could be used to improve the transportation characteristics of wood from restoration treatments and mill residues from the existing industry. By increasing bulk density and flowability, and decreasing moisture content, such depots could facilitate long-distance transportation to thriving markets in the Pacific Northwest or Asia. This would allow the region to capitalize on the extensive rail network that is often close to planned restoration activities [13].

\subsection{Southeast Region}

In the Southeastern US, timber lands are primarily under non-industrial private ownership. Most forest land is owned by individuals or organizations who have harvested trees from their land [26]. While there are several stressors (e.g., aging workforce, financial health, transportation) on the logging industry, logging capacity currently satisfies demand and some excess logging capacity exists [27]. The production of residual chips and bark is an important component of southern sawmill economics accounting for 30 to 40 percent of sawlog volumes [28]. Sawmills can affect the residual chip volume by altering incoming material specifications. Increased conversion efficiency of solid wood products generally indicates better mill revenue. Changing those limits can increase the volume and types of material delivered to the mill.

Chip mills and pellet plants are a common way to pre-process biomass and facilitate transportation in the Southeast. Enviva Company is exploring changes to its traditional supply chains by sourcing feedstocks from wood chip mills and/or from suppliers that dry chips in-woods before delivery to pellet mills [29]. Throughout the region, substantial quantities of biomass are processed into wood pellets to serve export markets in Europe, providing one example of a bio-hub. In this case, the depots are located in the southeastern U.S. and provide a uniform feedstock (pellets) to central processing facilities in Europe.

With local market support, harvesting trees and producing bioenergy as a co-product has been viable across the southeast. Co-production of biomass with roundwood typically minimizes cost since incremental or marginal costs are quite low and volume per piece is maximized. Among bioenergy producers in Virginia, nearly all produced roundwood and bioenergy as co-products [30]. While chip production costs decline with increased chip volume, higher biomass volumes could increase roundwood costs by interfering with production [31]. Shresthra and Lanford (2002) [32] found that marketing pulp chips and logs increased total yield compared to roundwood only harvests, but diversion of roundwood to chips reduced total value.

Biomass harvests are currently uneconomical as single product silvicultural treatments. Most multi-product harvests require product separation at landings, and perhaps merchandising again at the mill or woodyard. The intensity and methods used in product 
separation are primarily driven by differentiation in available markets. Most benefits from increased processing and sorting are related to avoidance of quota limits through diversification of markets [33] However, beyond some threshold of three to five products, sorting can have a negative impact on harvesting and landowner revenue. For very low value products like biomass, the products can be left onsite without significant impact [34]. Since the production of biomass co-products is dependent on the presence of multi-product harvesting, wood energy facilities are viewed as significant competitors by traditional fiber mills [35].

In summary, the previous section provides an overview of the current status and potential of forest bio-hubs in 3 regions. In the next section we focus on a SWOT analysis, reinforcing key points, and assessing future potential.

\section{Strengths, Weaknesses, Opportunities and Threats Analysis}

Strengths, Weaknesses, Opportunities, and Threats of bio-hub development vary between the three regions (Table 1). In this analysis, strengths and weaknesses refer to the potential positive or negative results of moving away from traditional supply chains towards bio-hub models. Opportunities and threats refer to changes that could either make a bio-hub approach more feasible or provide challenges to implementation.

The Pacific Northwest region is closest to having a bio-hub in place, with welldeveloped forest products industry, and several liquid biofuels facilities planned. Bio-hub strengths include de-risking the supply chain for the planned biorefineries. Weaknesses result from inefficiencies that such a model would bring, such as potentially longer transport distances and complicated chain-of-custody. There are opportunities to improve the feasibility of forest bio-hubs, such as incorporating under-utilized feedstock into supply chains, and using forest biomass as a biooil feedstock. Threats to bio-hub development in the Pacific northwest include a general lack of collaboration among firms and differences in transportation economics when considering east-side versus west-side forests (Table 1). Other threats include the capital costs associated with biorefinery development which can be $\$ 500$ million or more and require a guaranteed fuel supply. Further, woody biomass from harvesting residues is linked to timber harvest levels which in turn vary based on broad economic cycles. These factors can provide disincentives for landowners to enter into long term supply agreements.

The Southwest is unlikely to have a self-contained bio-hub. However, the region could provide depots to ship pre-processed woody byproducts outside the region. Strengths of this approach would be greater market access for under-utilized feedstock, thus improving the economics of forest restoration treatments. Weaknesses could be an overall increase in transportation distances. Opportunities to address these weaknesses include improving the infrastructure and utilization of railroad for shipping forest products, as well as a workforce training center. Policies favorable to forest bioenergy may provide opportunities to keep the material local, favoring a self-contained bio-hub. Threats stem primarily from the instability of wood supplies from national forests.

For the southeast region, more diverse and competitive markets could provide an opportunity for bio-hub development as co-production of roundwood and bioenergy feedstocks from harvesting operations. Recent developments in logging technology have increased product marketing options which in turn create greater economic incentives to retain private land holdings. There would be significant threats to depots that accept, process and transport material if the market destinations are also directly accessible by wood producers. Many current mills already manufacture primary products, and produce and market co-products, filling a role similar to depots. Thus, one scenario could include direct competition between depots and existing mills for raw materials. 
Table 1. Regional summary of strengths, weaknesses, opportunities, and threats of a bio-hub model compared with traditional supply chains. General items (not specific to a region) are discussed in the paper's Introduction.

\begin{tabular}{|c|c|c|c|}
\hline & Pacific Northwest (PNW) & Southwest (SW) & Southeast (SE) \\
\hline $\begin{array}{l}\text { Advantages of bio-hub } \\
\text { compared with } \\
\text { a traditional supply } \\
\text { chain? }\end{array}$ & 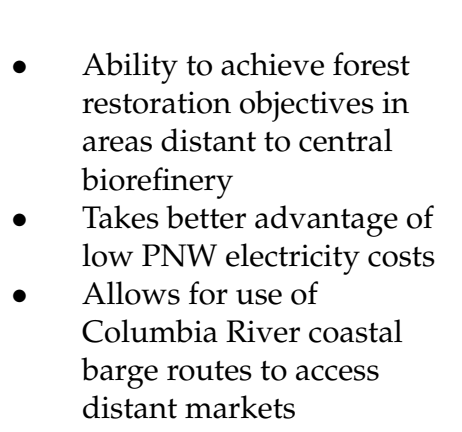 & $\begin{array}{l}\text { Greater market access to } \\
\text { achieve forest restoration } \\
\text { objectives throughout } \\
\text { region } \\
\text { Increased utilization of } \\
\text { neglected feedstock in } \\
\text { CFLRPs }\end{array}$ & $\begin{array}{l}\text { Enhanced } \\
\text { roundwood/bioenergy } \\
\text { co-production } \\
\text { Incentive for landowners } \\
\text { to retain private land as } \\
\text { forests } \\
\text { - Provide market for } \\
\text { secondary wood products } \\
\text { from sawmills }\end{array}$ \\
\hline $\begin{array}{c}\text { Disadvantages of } \\
\text { bio-hub compared with } \\
\text { a traditional supply } \\
\text { chain? }\end{array}$ & $\begin{array}{l}\text { - May increase total } \\
\text { transport distance if not } \\
\text { optimized } \\
\text { Complicates log } \\
\text { accounting and } \\
\text { chain-of-custody for } \\
\text { certified products }\end{array}$ & $\begin{array}{l}\text { Limited suitable locations } \\
\text { for intermediary } \\
\text { processing facilities, } \\
\text { requiring long-distance } \\
\text { transportation } \\
\text { May shift job creation and } \\
\text { wood product markets } \\
\text { away from the region }\end{array}$ & $\begin{array}{l}\text { Lack of advantages and } \\
\text { needs for bio-hub based } \\
\text { supply chains due to } \\
\text { existing opportunities for } \\
\text { direct sale of most forest } \\
\text { products } \\
\text { Handling biomass can } \\
\text { interfere with higher-value } \\
\text { roundwood production } \\
\text { Limited experience in } \\
\text { running sort yard } \\
\text { operations }\end{array}$ \\
\hline $\begin{array}{c}\text { How to improve } \\
\text { feasibility of developing } \\
\text { bio-hub? }\end{array}$ & $\begin{array}{l}\text { - Incorporate under-utilized } \\
\text { feedstock into supply } \\
\text { chains } \\
\text { - } \quad \text { Improve truck scheduling } \\
\text { - } \quad \text { Forest biomass } \\
\text { competition in biooil } \\
\text { markets } \\
\text { - Capitalize on } \\
\text { well-established forest } \\
\text { products industry } \\
\text { infrastructure }\end{array}$ & $\begin{array}{l}\text { - Promote policies favorable } \\
\text { to renewable energy and } \\
\text { improved biomass } \\
\text { utilization } \\
\text { Develop a workforce } \\
\text { training center } \\
\text { Utilize railroad network to } \\
\text { access distant markets } \\
\text { Capitalize on community } \\
\text { support for active forest } \\
\text { management and wood } \\
\text { utilization }\end{array}$ & $\begin{array}{l}\text { Capitalize on diverse array } \\
\text { of land ownership and } \\
\text { forest products markets } \\
\text { Increase efficiency of } \\
\text { in-woods separation } \\
\text { - Whole-tree delivery to } \\
\text { processing centers } \\
\text { Enhance use of logging } \\
\text { residues and mill } \\
\text { byproducts }\end{array}$ \\
\hline $\begin{array}{c}\text { What may stand in the } \\
\text { way of developing } \\
\text { bio-hub? }\end{array}$ & $\begin{array}{l}\text { Lack of collaboration } \\
\text { among firms } \\
\text { - West of Cascades many } \\
\text { sources are relatively short } \\
\text { transport distances from } \\
\text { forest to mill. } \\
\text { East of Cascades timber } \\
\text { supply from National } \\
\text { Forests long- and short } \\
\text { term }\end{array}$ & $\begin{array}{l}\text { Timber supply from } \\
\text { National Forests: long- } \\
\text { and short-term } \\
\text { Limited forestry workforce } \\
\text { and contractors } \\
\text { Local opposition to } \\
\text { moving wood products } \\
\text { out of the region }\end{array}$ & $\begin{array}{l}\text { - Competition for biomass } \\
\text { among forest products } \\
\text { companies } \\
\text { Negative impact of } \\
\text { biomass on harvesting and } \\
\text { landowner revenue } \\
\text { Pellet manufacturers and } \\
\text { co-generation facilities } \\
\text { viewed as competitors }\end{array}$ \\
\hline
\end{tabular}

The SWOT approach helps to determine if a bio-hub model would be appropriate and, if so what it may look like. For example, the strengths of a bio-hub model may not outweigh the weaknesses, as in certain parts of the PNW or Southeast where transport distances are already short. This could influence the configuration of the forest bio-hubs (Figure 1b). On the other hand, bio-hub strengths could outweigh the weaknesses but with significant threats to implementation that would need to be addressed. This could be the case in the Southwest, where limited workforce and instable wood supply may cause problems. It 
would be necessary to resolve these threats to justify the investment necessary in bio-hub infrastructure. Therefore, future research on bio-hub feasibility could rate strengths and weaknesses quantitatively on site-specific locations. Relevant criteria could include biomass supplies, prices, products, markets, and capital investment requirements.

\section{Discussion}

Forest bio-hubs represent a new paradigm for biomass supply chains in the U.S., and can increase flexibility from the woods to a central processing facility. In many cases, they represent a model to enhance optimal use of all parts of a tree. They are flexible in the sense that, although broadly classified as being distributed or centralized, many types of configurations are possible. For example, bio-hub depots can process biomass, then feed one or more centrally located processing facilities. Distributed models are also possible, where multiple forest depots may be present and feedstocks may be transported directly from outlying sources to a centralized biorefinery [36]. Lamers et al. (2015b) [5] indicate two primary designs. Standard depots can function primarily to improve supply stability, while quality depots can increase feedstock quality by pre-processing raw materials at a bio-hub.

\subsection{Bio-Hub Configurations Must Be Tailored to the Unique Characteristics of a Region}

The scale of operation has a direct bearing on supply chains and the design of bio-hub networks. The well-developed wood processing industries of the Pacific Northwest and the Southeast could lend themselves toward large-scale bio-hub development. At larger scales, biorefineries may produce cellulosic ethanol, aviation fuels, and related products, requiring more sophisticated designs. At smaller scales, in-woods depots could be used primarily to provide stability in feedstock supplies [5], providing dependable supplies to one or more wood products producers, either at a cluster site or strategically along the supply chain. Here, each producer could use a different feedstock component, encouraging niche products to be manufactured. In other cases, more traditional models including sort yards could be considered. Log sort yards often include at least minimal log processing operations, and share many of the same principles influencing the economic and practical feasibility of forest bio-hubs. Financially viable sort yards would need to consider local log supplies, wood market conditions, and the number of product sorts required, and this is especially true for small diameter timber [37].

In resource-rich regions in the U.S., forest bio-hubs are sometimes unneeded if sufficient feedstocks can be transported directly to a centralized facility at minimum cost. Here, the additional handling costs and transportation distances of intermediary processing centers outweigh the potential value added. This may be the case in some southeastern and northwestern locations.

A hallmark characteristic of forest bio-hubs is that some amount of intermediary processing occurs. This could be as simple as delimbing and/or air-drying, but could include further processing such as pelletizing or torrefaction. Often transportation economics are improved due to the pre-processing step which results in denser biomass having higher energy densities. This has been widely researched for agricultural residues (including corn stover), where pre-processing can include drying, size reduction, chemical processing, and blending [4]. Longer transportation distances can also allow feedstock supplies to remain uniform at the central processing facility, even when there is greater spatial and temporal variation for individual supply points.

The degree of in-woods processing also influences bio-hub performance. For example, the southeast region may have relatively simple in-woods operations since supply chains are well defined as are markets, including overseas pellet consumers in Europe. However, producing too many products may create operational inefficiencies due to greater sorting and handling requirements. Well-defined markets for pellets, lumber, and other products are present in the southeast, with a pulp and paper industry helping to drive supply chain infrastructure. 
By contrast, western forest bio-hubs may be driven more by a need to remove fireprone biomass from widely distributed areas. Pellet production, biochar, torrefied wood and pyrolysis oil have been investigated using mobile production facilities that can help improve economic feasibility versus fixed facility locations, especially when grid connections are available [38]. A torrefied wood facility under construction in John Day, Oregon will use fire-prone feedstocks from eastern Oregon. The growth of the cross-laminated timber industry in the west could help drive markets for its residues.

Land ownership also plays a role in feedstock availability. For example, in the Southeast, large areas of private ownership can supply wood pellet feedstocks for use in European markets, often as a cofiring fuel. In the western U.S., Federal ownership management goals favor lower harvest levels for conventional products. In some cases, in-woods biomass must be removed after timber harvest operations on Federal lands, or in the absence of conventional harvests.

Each region discussed in this paper has unique conditions, forest types, levels of fire risk, biomass supply, accessibility, wood products infrastructure, woody biomass feedstocks, and access to markets, among other factors. All directly influence the trajectory of bio-hub development as well as commercialization to support the emerging bioeconomy. Thus, there is no "one size fits all" to the design of forest bio-hubs, and they must be evaluated case by case. Since the expected benefits of establishing a bio-hub must justify the additional costs, techno-economic analyses can help identify viable scenarios, especially when multiple feedstocks, processing technologies, and products are involved [9]. Ultimately, new markets for higher-value cellulose products could help accelerate biomass supply development. In general, conditions conducive to forest industries development also bode well for bio-hub potential. These can include a large private and public land base, low electricity rates, barge and rail access, and a developed forestry infrastructure.

\subsection{The Emerging Bio-Economy and Replacement of Fossil Fuels}

Biorefineries producing products such as specialty chemicals, plastics, power, and heat, could reduce dependence on our largely fossil fuel-based economy. However, few if any wood-based biorefineries are currently in operation, although planned facilities could produce liquid transportation fuels in the near future. Additional bio-based feedstocks, including agricultural residues, municipal wastes, and other organic wastes could be coprocessed with woody feedstocks. Bals and Dale (2012) [9] investigated fast pyrolysis of woody biomass in the Midwest, finding that it generated low positive returns, and was less profitable than corn stover processes. Using a mix of agricultural and woody feedstocks would increase complexity since all have different supply chain structures, feedstock variability, "shelf lives", and feedstock values.

A key advantage of biorefineries is the potential for using current infrastructure from fossil fuel refineries, thus reducing the need to build new infrastructures for biomass feedstocks [39]. The "circular" economy would include integrated biorefineries using various biomass feedstocks and conversion pathways to produce biofuels and biochemicals [40]. Brandt et al. (2018) [41] evaluated the mechanical processes to produce cellulosic sugars as well as fuel pellets as a co-product. Economic feasibility could be enhanced if Renewable Identification Number (RIN) credits were available, and the biofuel facility and sugar production facility were co-located. Thus, in addition to broad macroeconomic factors, successful forest bio-hubs will depend on an array of technical, economic, and social factors, which need to be evaluated based on site-specific conditions.

\subsection{Forest Bio-Hubs to Support Forest Health and Reduce Fire Risk}

Forest bio-hubs could benefit fire risk reductions, particularly on western landscapes. Restoration contracts in the Southwest often require that biomass be removed from the forest, increasing the need for forest bio-hubs to receive and process material. Thus, optimal biomass use could depend on both market factors and ecosystem service that are either required by policy or are demanded by consumers. Properly constructed forest depots 
can buffer supply chain disruptions, allowing more predictable material flow from forest to manufacturing center. The feedstocks available could include fire salvage and beetle salvage timber in addition to biomass from mechanically treated stands.

Fire risk reduction is likely to gain importance as climate change can contribute to wildfire severity especially near population centers. Societal values seem to be changing in this regard, and biomass supply chain optimization now includes economic, social and environmental considerations [42]. For example, the International Union for Conservation of Nature's red list provides information about range, population size, habitat, threats, and conservation actions of threatened plant species. At the same time, wildfire events are no longer just an issue for remote communities, as larger cities (Napa Valley, California; Portland, Oregon) have become affected by smoke, watershed degradation, and potential threats of evacuation. New wildfire suppression strategies may be needed, including optimal timing of small fire suppression to prevent further growth (especially with unpredictable weather events). Greater attention to fire risk reduction activities, particularly in western states, would not only improve forest health but also build resilience in forest-dependent communities.

Western states vary greatly in the extent and utilization of forest resources, the proportion of land under federal ownership, and community and stakeholder structure and dynamics. Thus, forest bio-hubs will require site-specific evaluations that are needed to justify their implementation when accommodating small-diameter materials and primary residues [43]. However, when forest restoration treatments are used as a source of biomass to forest bio-hubs, a range of socioeconomic and ecosystem service benefits can also be realized. For example, water quality values can be preserved when forest treatments reduce wildfire risk, improving forest health in municipal watersheds. Sustainable economic development can be enhanced when considering the employment needs of all stages of the biomass supply chain. Finally, innovation can spur new markets and technologies, such as biofuels, for use in the aviation industry, torrefied wood, and/or mobile pyrolysis, all of which could benefit from successful bio-hub implementation.

Properly designed and implemented forest bio-hubs support forest health in the following ways:

- Sustainable forest management does not lead to deforestation since net harvests and net growth should be in balance

- In many forest ecosystems, including those addressed in this paper, forests that are left alone (i.e., unmanaged) are likely to experience drought, fire, or insect infestations, in part brought upon by climate change

- Forests managed for climate adaptation and mitigation often result in the generation biomass materials having little or no economic value. Forest biohubs are one avenue for marketing these otherwise unmerchantable materials, and this is especially the case for privately owned forests.

Due to the myriad social and environmental benefits of wildfire risk reduction in the Southwest, there has been an increase in alternative funding sources to get this work done. Since the timber often has negative net value, other sources of funding are used including federal, state, private, and conservation finance [44]. An innovative new approach for funding is the Forest Resilience Bond, which is an example where public-private partnerships and private capital are leveraged to fund forest restoration projects [45]. Traditionally, the economic benefits of forest restoration have been difficult to quantify, only materializing far in the future as "avoided costs" of a wildfire that may not have actually occurred. The Forest Resilience Bond relies on contracts with beneficiaries (e.g., landowners, water utilities) and investors (e.g., pension funds, foundations) to provide more immediate payoffs [45]. Thus, projects can move forward even if the timber has a net negative value by the time it is delivered to the mill. The bio-hub concept can expand the feasible distance that harvested biomass may travel, and possibly increase value. 


\section{Conclusions}

This research has considered bio-hub potential in three U.S. regions. Forest bio-hubs could become a new supply chain paradigm for biomass feedstocks to reach processing centers economically, supporting an emerging bioeconomy. Innovation and adaptability will play key roles in forest bio-hub development. Several factors, including forest type, land ownership, scale of operation, forest products infrastructure, and current markets will require careful attention in bio-hub design. Biomass transportation chains that minimize supply risks will be needed before large investment decisions can be made. Effective forest bio-hubs will not only provide local economic benefits but also provide important ecosystem services while supporting forest health and reducing fire risk, especially in western forests.

Author Contributions: Conceptualization, D.N.; methodology, D.N. and D.V.; investigation, H.-S.H., J.S., D.V., D.M. and M.S.; writing —original draft preparation, H.-S.H., J.S., D.V., D.M., M.S. and D.N.; writing—review and editing, D.V.; project administration, D.N. All authors have read and agreed to the published version of the manuscript.

Funding: No external funding was utilized in this work.

Informed Consent Statement: Not applicable.

Acknowledgments: We want to thank Thomas Schuler, USDA Forest Service, for his insights, valuable comments, and helpful guidance throughout this work.

Conflicts of Interest: The authors declare no conflict of interest. The funders had no role in the design of the study; in the collection, analyses, or interpretation of data; in the writing of the manu-script, or in the decision to publish the results.

\section{References}

1. US EPA. Final Renewable Fuel Standards for 2020, and the Biomass-Based Diesel Volume for 2021. Available online: https: / /www.epa.gov/renewable-fuel-standard-program/final-renewable-fuel-standards-2020-and-biomass-based-dieselvolume\#rule-summary (accessed on 29 October 2021).

2. Nicholls, D.L.; Halbrook, J.M.; Benedum, M.E.; Han, H.S.; Lowell, E.C.; Becker, D.R.; Barbour, R.J. Socioeconomic constraints to biomass removal from forest lands for fire risk reduction in the Western U.S. Forests 2018, 9, 264. [CrossRef]

3. Lamers, P.; Tan, E.C.D.; Searcy, E.M.; Scarlata, C.J.; Cafferty, K.G.; Jacobson, J.J. Strategic Supply System Design-A Holistic Evaluation of Operational and Production Cost for a Biorefinery Supply Chain. Biofuel. Bioprod. Biorefin. 2015, 9, 648-660. [CrossRef]

4. Argo, A.; Tan, E.; Inman, D.; Langholtz, M.; Eaton, L.; Jacobson, J.; Wright, C.; Muth, D.J.; Wu, M.M.; Chiu, Y.; et al. Investigation of biochemical biorefinery sizing and environmental sustainability impacts for conventional bale system and advanced uniform biomass logistics designs. Biofuel. Bioprod. Biorefin. 2013, 7, 282-302. [CrossRef]

5. Lamers, P.; Roni, M.S.; Tumuluru, J.S.; Jacobson, J.J.; Cafferty, K.G.; Hansen, J.K.; Kenney, K.; Teymouri, F.; Bals, B. Technoeconomic analysis of decentralized biomass processing depots. Bioresour. Technol. 2015, 194, 205-213. [CrossRef]

6. Muth, D.J; Langholtz, M.H.; Tan, E.C.D.; Jacobson, J.J.; Schwab, A.; Wu, M.M.; Argo, A.; Brandt, C.C.; Cafferty, K.G.; Chiu, Y.-W.; et al. Investigation of thermochemical biorefinery sizing and environmental sustainability impacts for conventional supply system and distributed pre-processing supply system designs. Biofuel. Bioprod. Biorefin. 2014, 8, 545-567. [CrossRef]

7. Martinkus, N.; Latta, G.; Brandt, K.; Wolcott, M. A multi-criteria decision analysis approach to facility siting in a wood-based depot-and-biorefinery supply chain model. Front. Energy Res. 2018, 6, 124. [CrossRef]

8. International Energy Agency. 2020. Task 43- Biomass Supply. Available online: https://task43.ieabioenergy.com/ (accessed on 29 October 2021).

9. Bals, B.D.; Dale, B.E. Developing a Model for Assessing Biomass Processing Technologies within a Local Biomass Processing Depot. Bioresour. Technol. 2012, 106, 161-169. [CrossRef]

10. Sterbova, M.; Loucanova, E.; Palus, H.; Ivan, L.; Salka, J. Innovation Strategy in Slovak Forest Contractor Firms-A SWOT Analysis. Forests 2016, 7, 118. [CrossRef]

11. Eranki, P.L.; Manowitz, D.H.; Bals, B.D.; Izaurralde, C.; Kim, S.; Dale, B.E. The watershed-scale optimized and rearranged landscape design (WORLD) model and local biomass processing depots for sustainable biofuel production: Integrated life cycle assessments. Biofuel. Bioprod. Biorefin. 2013, 7, 537-550. [CrossRef]

12. Kline, K.L.; Dale, V.H.; Rose, E.; Tonn, B. Effects of Production of Woody Pellets in the Southeastern United States on the Sustainable Development Goals. Sustainability 2021, 13, 821. [CrossRef]

13. Halbrook, J.; Han, H.-S. Chip \& Ship: Testing the Logistics of Supplying Wood Chips over Long Distance Using Intermodal Railroad Transportation; Northern Arizona University Ecological Restoration Institute: Flagstaff, AZ, USA, 2019; 28p. 
14. Brodbeck, A. Timber Industry Consolidation and the Need for Scale Appropriate Harvesting Mechanisms in Alabama's Black Belt. Master's Thesis, Auburn University, Auburn, AL, USA, 2005; 170p.

15. USDA Forest Service. Collaborative Forest Landscape Restoration Program, Washington, DC, USA. 2019. Available online: https:/ / www.fs.fed.us/restoration/CFLRP/ (accessed on 29 October 2021).

16. Schultz, C.A.; Jedd, T.; Beam, R.D. The Collaborative Forest Landscape Restoration Program: A History and Overview of the First Projects. J. For. 2012, 110, 381-391. [CrossRef]

17. Chan, C. Supporting Local Rural Economies while Improving Forest Health, Washington, DC, USA. 2017. Available online: https:/ / www.usda.gov/media/blog/2015/06/22/supporting-local-rural-economies-while-improving-forest-health (accessed on 25 January 2022).

18. Anderson, N.; Mitchell, D. Forest operations and woody biomass logistics to improve efficiency, value, and sustainability. Bioenergy Res. 2016, 9, 518-533. [CrossRef]

19. Rummer, B.; Klepac, J.; Thompson, J. Technology for biomass feedstock production in southern forests and GHG implications. In Proceedings of the 16th Biennial Southern Silvicultural Research Conference; Butnor, J.R., Ed.; e-Gen. Tech. Rep. SRS-156; US Department of Agriculture Forest Service, Southern Research Station: Asheville, NC, USA, 2012; Volume 156, pp. $278-282$.

20. Iversen, K.; Van Demark, R. Integrating fuel reduction management with local bioenergy operations and businesses-A community responsibility. Biomass Bioenergy 2006, 30, 304-307. [CrossRef]

21. City of Flagstaff, Arizona, Flagstaff Ranger District, Coconino National Forest. Flagstaff Watershed Protection Project Executive Summary \& Implementation Plan. 2012; 16p. Available online: https:/ /www.flagstaff.az.gov/DocumentCenter/View /41236/ Ex-Summ-Impl-Plan_Dec12?bidId= (accessed on 29 October 2021).

22. Huang, C.H.; Finkral, A.; Sorensen, C.; Kolb, T. Toward full economic valuation of forest fuels-reduction treatments. J. Environ. Manag. 2013, 130, 221-231. [CrossRef]

23. Lynch, D.L. What do forest fires really cost? J. For. 2004, 102, 42-49.

24. Nicholls, D. Forest Products Cluster Development in Central Arizona-Implications for Landscape-Scale Forest Restoration; Gen. Tech. Rep. PNW-GTR-898; U.S. Department of Agriculture, Forest Service, Pacific Northwest Research Station: Portland, OR, USA, 2014; 18p.

25. Vaughan, D.R.; Edgeley, C.; Han, H.-S. Forest contracting businesses in the US Southwest: Current profile and workforce training needs. J. For. 2021, in press.

26. Butler, B.J.; Wear, D.N. Forest ownership dynamics of southern forests. In The Southern Forest Futures Project: Technical Report; Wear, D.N., Greis, J.G., Eds.; Gen. Tech. Rep. SRS-GTR-178; USDA-Forest Service, Southern Research Station: Asheville, NC, USA, 2013; pp. 103-121.

27. Conrad, J.L., IV; Greene, W.D.; Hiesl, P. A review of changes in US logging businesses 1980s-Present. J. For. 2018, 116, 291-303. [CrossRef]

28. Steele, P.H.; Risbrudt, C.D. Efficiency of softwood sawmills in the southern United States in relation to capacity. Prod. J. 1985, 35, 51-56.

29. Cesafsky, K.D.; (Chief Sustainability Officer, Enviva Corporation, Tokyo, Japan). Personal communication, 2019.

30. Barrett, S.M.; Bolding, M.C.; Aust, W.M.; Munsell, J.F. Characteristics of logging businesses that harvest biomass for energy production. For. Prod. J. 2014, 64, 265-272. [CrossRef]

31. Baker, S.A.; Westbrook, M.D., Jr.; Greene, W.D. Evaluation of integrated harvesting systems in pine stands of the southern United States. Biomass Bioenergy 2010, 34, 720-727. [CrossRef]

32. Shresthra, S.P.; Lanford, B.L. Comparison of timber utilization between a tree-length and an in-wood chipping harvesting operations. In Forest Engineering Challenges: A Global Perspective, Proceedings of the 25th Annual Council on Forest Engineering Meeting, Auburn, AL, USA, 16-20 June 2002; Council on Forest Engineering: Corvallis, OR, USA, 2002; 5p.

33. Cass, R.D.; Baker, S.A.; Greene, W.D. Cost and productivity impacts of product sorting on conventional ground-based timber harvesting operations. Prod. J. 2009, 59, 108-114. [CrossRef]

34. Grushecky, S.T.; Wang, J.; Mcgill, D.W. Influence of site characteristics and costs of extraction and trucking on logging residue utilization in southern West Virginia. Prod. J. 2007, 57, 63-67.

35. Conrad, J.L., IV; Bolding, M.C.; Smith, R.L.; Aust, W.M. Wood-energy market impact on competition, procurement practices, and profitability of landowners and forest products industry in the US south. Biomass Bioenergy 2011, 35, 280-287. [CrossRef]

36. Ng, R.T.L.; Kurniawan, D.; Wang, H.; Mariska, B.; Wu, W.; Maravelias, C.T. Integrated framework for designing spatially explicit biofuel supply chains. Appl. Energy 2018, 216, 116-131. [CrossRef]

37. Han, H.-S.; Bilek, E.M.; Dramm, J.; Loeffler, D.; Calkin, D. Financial Feasibility of a Log Sort Yard Handling Small-Diameter Logs: A Preliminary Study. West. J. Appl. For. 2011, 26, 174-182. [CrossRef]

38. Berry, M.; Sessions, J. The Economics of Biomass Logistics and Conversion Facility Mobility: An Oregon Case Study. Appl. Eng. Agric. 2018, 34, 57-72. [CrossRef]

39. Kumar, B.; Verma, P. Biomass-based biorefineries: An important architype towards a circular economy. Fuel 2021, 288, 119622. [CrossRef]

40. Kohli, K.; Prajapati, R.; Sharma, B.K. Review Bio-Based Chemicals from Renewable Biomass for Integrated Biorefineries. Energies 2019, 12, 233. [CrossRef] 
41. Brandt, K.L.; Gao, J.; Wang, J.; Wooley, R.J.; Wolcott, M. Techno-Economic Analysis of Forest Residue Conversion to Sugar Using Three-Stage Milling as Pretreatment. Front. Energy Res. 2018, 6, 77. [CrossRef]

42. Cambero, C.; Sowlati, T. Assessment and optimization of forest biomass supply chains from economic, social and environmental perspectives-A review of literature. Renew. Sustain. Energy Rev. 2014, 36, 62-73. [CrossRef]

43. Mirkouei, A.; Haapala, K.R.; Sessions, J.; Murthy, G.S. A review and future directions in techno-economic modeling and optimization of upstream forest biomass to bio-oil supply chains. Renew. Sustain. Energy Rev. 2017, 67, 15-35. [CrossRef]

44. Blackmer, E.D.; Christian, L.J.; Conway, R.T. Building a Stewardship Economy: Insights from Community Innovation in the Rural American West. Master's Thesis., University of Michigan School for Environment and Sustainability, Ann Arbor, MI, USA, 2020; 186p.

45. Madeira, L.; Gartner, T. Forest Resilience Bond Sparks Innovative Collaborations Between Water Utilities and Wide-Ranging Stakeholders. J. -Am. Water Work. Assoc. 2018, 110, 42-49. [CrossRef] 